\title{
tRNA residues evolved to promote translational accuracy
}

\author{
IRINA SHEPOTINOVSKAYA and OLKE C. UHLENBECK ${ }^{1}$ \\ Department of Molecular Biosciences, Northwestern University, Evanston, Illinois 60208, USA
}

\begin{abstract}
The decoding properties of 22 structurally conservative base-pair and base-triple mutations in the anticodon hairpin and tertiary core of Escherichia coli RRNA $^{\mathrm{Ala}}{ }_{\text {GGC }}$ were determined under single turnover conditions using $E$. coli ribosomes. While all of the mutations were able to efficiently decode the cognate GCC codon, many showed substantial misreading of near-cognate GUC or ACC codons. Although all the misreading mutations were present in the sequences of other $E$. coli tRNAs, they were never found among bacterial tRNA ${ }^{\mathrm{Ala}}{ }_{\text {GGC }}$ sequences. This suggests that the sequences of bacterial tRNA ${ }^{\text {Ala }}{ }_{\text {GGC }}$ have evolved to avoid reading incorrect codons.
\end{abstract}

Keywords: protein synthesis; ribosome

\section{INTRODUCTION}

Bacterial tRNAs possessing the same anticodon have a characteristic set of sequence restrictions distributed throughout the molecule that distinguish them from tRNAs with different anticodons (Saks and Conery 2007; Targanski and Cherkasova 2008). These multivalent tRNA consensus sequences reflect evolutionary adaptations that permit each tRNA to function with its particular combination of amino acid and anticodon without compromising translational rate and accuracy. Different parts of a tRNA consensus "tune" different steps in translation. tRNA identity residues that are required for specific aminoacylation of each tRNA by its associated aminoacyl synthetase tend to be conserved among bacteria and usually include the anticodon and several residues at other locations in the molecule (Saks et al. 1994; Giege et al. 1998; Ardell 2010). Three base pairs in the T-stem adjust the affinity of each aminoacyl-tRNA to elongation factor $\mathrm{Tu}$ to be tight enough to form a complex but weak enough to release from the protein during translation (Schrader et al. 2011). These T-stem base pairs are not conserved among bacteria, but each tRNA species uses different combinations of the three base pairs to achieve the requisite affinity (Schrader and Uhlenbeck 2011). In this communication, we show that many of the consensus residues present in the anticodon hairpin and the tertiary core of Escherichia coli tRNA $^{\mathrm{Ala}}{ }_{\mathrm{GGC}}$ have evolved to minimize misreading of incorrect codons during decoding on the ribosome.

\footnotetext{
${ }^{1}$ Corresponding author

E-mail o-uhlenbeck@northwestern.edu

Article published online ahead of print. Article and publication date are at http://www.rnajournal.org/cgi/doi/10.1261/rna.036038.112.
}

\section{RESULTS AND DISCUSSION}

Mutations of E. coli tRNA ${ }^{\text {Ala }}$ GGC were evaluated for their ability to decode their correct (cognate) GCC codon and incorrect (near-cognate) GUC and ACC codons. This tRNA was chosen because it is a member of the most common and best studied D4V5 structural class and because it is one of the few in E. coli that lacks post-transcriptional modifications in the anticodon hairpin, which are known to affect both the rate and accuracy of ribosomal decoding (Hagervall et al. 1990; Harrington et al. 1993; Li et al. 1997; Urbonavicius et al. 2001, 2003; Murphy et al. 2004; Agris 2008). Previous experiments have shown that unmodified tRNA ${ }_{\text {GGC }}^{\text {Ala }}$ able to decode with a similar rate and accuracy as the fully modified form, permitting the functional analysis of unmodified mutant tRNAs prepared by in vitro transcription (Ledoux et al. 2009). The expected tertiary structure and the consensus of tRNA ${ }^{\text {Ala }}$ GCC were used together to guide the selection of mutations of the five Watson-Crick and two noncanonical base pairs in the anticodon hairpin and the five base pairs and triples in the tertiary core of the molecule (Fig. 1; Table 1). Two general classes of mutations were chosen. Consensus mutations changed residues in the E. coli tRNA ${ }_{\text {GGC }}^{\text {Ala }}$ sequence to residues present at the correspond-

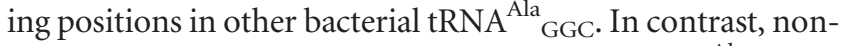
consensus mutations are changes in $E$. coli $\mathrm{tRNA}_{\mathrm{GGC}}^{\mathrm{Ala}}$ to residues that are either never or very rarely $(<2 \%)$ found among other bacterial tRNA ${ }^{\mathrm{Ala}}{ }_{\text {GGC }}$ sequences but are present in other tRNAs of the D4V5 structural class. For example, E. coli tRNA ${ }_{\text {GCC }}^{\mathrm{Ala}}$ has a C31-G39 base pair, while G31-C39 is present in this tRNA in many other bacteria, so the introduction of G31-C39 into E. coli tRNA $^{\mathrm{Ala}}$ is termed a consensus mutation. However, the U31-A39 base pair is never found in any bacterial tRNA ${ }^{\mathrm{Ala}}{ }_{\mathrm{GGC}}$ but is present in many other 


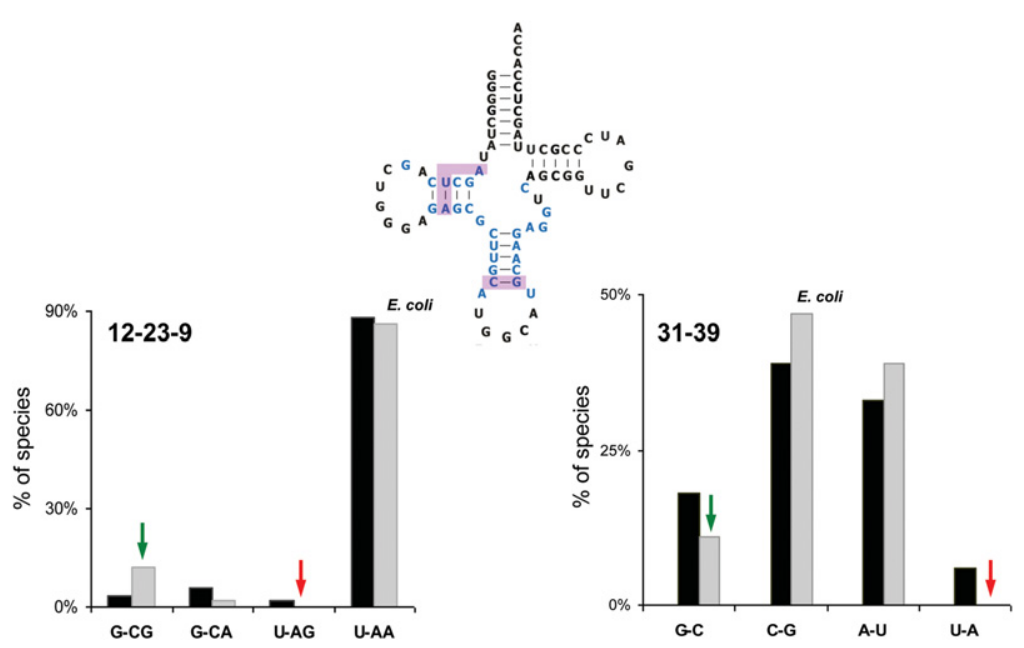

FIGURE 1. Using sequence conservation to direct the mutagenesis of nine base pairs and three base triples in the anticodon hairpin and tertiary core of E. coli tRNA ${ }_{\text {GGC }}^{\text {Ala }}$ (blue). The bar graphs compare the frequency of different 12-23-9 base triple sequences (left) and 31-39 base pair sequences (right) present among 97 bacterial tRNA ${ }_{\text {GGC }}^{\text {Ala }}$ (gray bars) with the corresponding sequences present among 3623 bacterial tRNAs of the D4V5 structural class (black bars). Nonconsensus mutations of $E$. coli tRNA ${ }_{\text {GGC }}^{\text {Ala }}$ (red arrows) are not present in any bacteria tRNA $^{\mathrm{Ala}}{ }_{\mathrm{GGC}}$ but are used in other tRNAs. Consensus mutations (green arrows) are present in tRNA ${ }_{\text {GGC }}^{\text {Ala }}$ from other species. Sequence conservation data and mutations chosen for all the base pairs and triples are in Table 1 .

D4V5 tRNAs, so introducing U31-A39 is termed a nonconsensus mutation. Since both consensus and nonconsensus mutations introduce residues present in other active tRNAs at the homologous position, the mutant tRNAs are likely to adopt a very similar structure. Combinations of residues 31-39 that are never found in any tRNA, such as most mismatched pairs, were not studied since they could potentially misfold. The same strategy was used to make mutations in the base pairs and base triples present in the core of tRNA, although this part of the molecule is so conserved among bacterial tRNA ${ }_{\text {GGC }}^{\text {Ala }}$ that consensus mutations could not always be identified. Furthermore, since the tertiary core is quite conserved for all tRNAs of the D4V5 class, even the choice of potential nonconsensus mutations was limited. This evolutionary approach for choosing mutations maximizes the chance of finding functional changes in tRNA while minimizing disruption of the folded structure of tRNA. Six consensus and 16 nonconsensus mutations throughout the anticodon helix and core of Ala-tRNA ${ }_{\text {GGC }}$ were chosen in this study (Table 1). When multiple choices for mutations in each category were available, no systematic secondary criterion was used.

Native tRNA ${ }_{\text {GGC }}^{\text {Ala }}$, the unmodified wild type, and the 22 mutations were evaluated for their ability to decode cognate and near-cognate codons by measuring the rate and extent of dipeptide formation using E. coli ribosomes. Since peptide bond formation is the final step in decoding, any mutation that causes a defect at an earlier step can potentially also be detected. The assay uses a rapid mixing device to combine a $0.2 \mu \mathrm{M}$ ternary complex containing $\left[3^{\prime}-\mathrm{P}^{32}\right]$-labeled Ala-
tRNA with $1 \mu \mathrm{M} 70 \mathrm{~S}$ ribosomes containing an mRNA fragment with the appropriate codon in the A site and fMettRNA $^{\text {fMet }}$ in the P site (Ledoux and Uhlenbeck 2008a). Reactions were performed in a "high fidelity" buffer containing polyamines and a low concentration of magnesium ions to ensure accurate decoding (Gromadski and Rodnina 2004). At differing times, the reactions were quenched, treated with P1 nuclease, subjected to thin-layer chromatography to separate the $\mathrm{P}^{32}$-labeled Ala-AMP starting material from the fMet-Ala-AMP product and quantitated using a phosphorimager. The initial concentrations of ternary complex and ribosomes were chosen to be subsaturating for both cognate and nearcognate codons in order to maximize detection of an altered rate or extent of decoding when screening the mutant tRNAs. Since an excess of EF-Tu $\cdot G T P$ over aa-tRNA was used to ensure efficient formation of ternary complex, and the ternary complex was not purified, a high concentration of a noncognate aa-tRNA was included to sequester any free EF-Tu•GTP after mixing and thereby prevented any Ala-tRNA released from ribosomes during proofreading from rebinding EF-Tu•GTP and undergoing a second round of decoding (Supplemental Fig. 1; Pan et al. 2008).

A sample data set for the two 31-39 mutations is shown in Figure 2A. As had been found previously (Ledoux et al. 2009), the unmodified wild-type tRNA ${ }_{\text {GGC }}^{\text {Ala }}$ shows rapid and efficient decoding on the cognate GCC codon, but little dipeptide is detected with the near-cognate GUC codon even after long incubation times. Such accurate in vitro decoding has been observed for several other aa-tRNAs (Cochella and Green 2005; Gromadski et al. 2006; Schrader et al. 2011; Johansson et al. 2012) and has been found to be a consequence of a combination of weak binding of the ternary complex to the near-cognate codon, a reduced rate of GTP hydrolysis due to poor induced fit, and efficient rejection of the near-cognate tRNA after GTP hydrolysis (Pape et al. 1999; Gromadski and Rodnina 2004; Rodnina 2012). Results using the consensus G31-C39 mutation are essentially identical to the wild-type tRNA. In contrast, the nonconsensus U31-A39 mutation functions normally on the GCC codon but shows substantial amounts of product accumulating at a similar rate on the near-cognate GUC codon. This behavior is consistent with a substantial fraction of the mutant tRNA molecules being able to escape proofreading by having a faster rate of accommodation and/or a slower rate of rejection compared to wild-type tRNA (Wohlgemuth et al. 2011). While additional experiments will be required 
TABLE 1. Percentages of base pairs and triples in 97 bacterial tRNA ${ }^{\text {Ala }}{ }_{\text {GGCS }}$ and 3623 D4V5 tRNAs

\begin{tabular}{|c|c|c|c|c|c|c|c|c|c|}
\hline \multicolumn{10}{|l|}{ Helical pairs } \\
\hline \multirow[t]{3}{*}{$27-43$} & & GC & GU & CG & $\mathrm{AU}$ & UA & UG & & \\
\hline & Ala & $0^{N}$ & 0 & $82^{*}$ & $1^{N}$ & 16 & 1 & & \\
\hline & Total & 8 & 8 & 48 & 12 & 16 & 3 & & \\
\hline \multirow{3}{*}{$28-42$} & & GC & GU & CG & $\mathrm{AU}$ & UA & UG & & \\
\hline & Ala & 4 & $0^{N}$ & 28 & $10^{\mathrm{C}}$ & $58^{*}$ & 0 & & \\
\hline & Total & 7 & 1 & 51 & 16 & 23 & 1 & & \\
\hline \multirow[t]{3}{*}{$29-41$} & & GC & CG & $\mathrm{AU}$ & UA & & & & \\
\hline & Ala & $5^{C}$ & $0^{N}$ & 32 & $63^{*}$ & & & & \\
\hline & Total & 27 & 20 & 15 & 37 & & & & \\
\hline \multirow[t]{3}{*}{$30-40$} & & GC & GU & CG & $\mathrm{AU}$ & UG & & & \\
\hline & Ala & $50^{*}$ & $0^{N}$ & 46 & 2 & 1 & & & \\
\hline & Total & 69 & 1 & 29 & 1 & 1 & & & \\
\hline \multirow[t]{3}{*}{$31-39$} & & GC & GU & CG & $\mathrm{AU}$ & UA & UG & & \\
\hline & Ala & $11^{\mathrm{C}}$ & 1 & $47^{*}$ & 39 & $0^{\mathrm{N}}$ & 1 & & \\
\hline & Total & 18 & 1 & 39 & 33 & 6 & 1 & & \\
\hline \multirow[t]{3}{*}{$11-24$} & & CG & UA & UG & & & & & \\
\hline & Ala & $97^{*}$ & $3^{C}$ & $0^{\mathrm{N}}$ & & & & & \\
\hline & Total & 93 & 5 & 1 & & & & & \\
\hline \multicolumn{10}{|c|}{ Nonhelical pairs } \\
\hline \multirow[t]{3}{*}{$32-38$} & & CG & $\mathrm{CA}$ & $\mathrm{AU}$ & $\mathrm{AC}$ & $\mathrm{AA}$ & UA & UU & UC \\
\hline & Ala & $26^{\mathrm{C}}$ & 0 & $66^{*}$ & 8 & 0 & $0^{N}$ & 0 & 0 \\
\hline & Total & 2 & 49 & 3 & 1 & 3 & 22 & 6 & 7 \\
\hline \multirow[t]{3}{*}{$26-44$} & & GU & GA & $\mathrm{CU}$ & $\mathrm{AU}$ & $\mathrm{AC}$ & AG & AA & \\
\hline & Ala & 0 & $74^{*}$ & $0^{N}$ & $0^{\mathrm{N}}$ & 1 & 20 & 2 & \\
\hline & Total & 1 & 32 & 2 & 8 & 6 & 35 & 14 & \\
\hline \multirow[t]{3}{*}{$15-48$} & & GC & $\mathrm{AU}$ & $\mathrm{AC}$ & UG & & & & \\
\hline & Ala & $87^{*}$ & $2^{N}$ & 2 & 3 & & & & \\
\hline & Total & 88 & 10 & 1 & 0 & & & & \\
\hline \multicolumn{10}{|l|}{ Base triples } \\
\hline \multirow[t]{3}{*}{ 12-23-9 } & & GCG & GCA & UAA & UAG & & & & \\
\hline & Ala & $12^{\mathrm{C}}$ & 2 & $86^{*}$ & $0^{N}$ & & & & \\
\hline & Total & 3 & 6 & 88 & 2 & & & & \\
\hline \multirow[t]{3}{*}{$10-25-45$} & & GCG & GCA & GCU & GUG & GUU & & & \\
\hline & Ala & $94^{*}$ & $0^{\mathrm{N}}$ & $1^{\mathrm{N}}$ & 4 & 1 & & & \\
\hline & Total & 77 & 1 & 13 & 8 & 1 & & & \\
\hline \multirow[t]{3}{*}{$13-22-46$} & & CGG & UAA & UGG & UGA & & & & \\
\hline & Ala & $99 *$ & $0^{N}$ & $0^{N}$ & 1 & & & & \\
\hline & Total & 98 & 1 & 1 & 0 & & & & \\
\hline
\end{tabular}

Rounding and omission of rare pairs can result in sums of $<100 \%$. $\left({ }^{*}\right)$ Base pair or triple present in $E$. coli tRNA ${ }_{\text {GGC, }}(\mathrm{C})$ the consensus, and $(\mathrm{N})$ nonconsensus mutation chosen for this study. order of $1 \mathrm{sec}^{-1}$ at $0.5 \mu \mathrm{M} 70 \mathrm{~S}$ ribosomes (data not shown). These rates are similar to $k_{\text {pep }}$ values observed for a number of native E. coli tRNAs and unmodified tRNA transcripts (Cochella and Green 2005; Ledoux and Uhlenbeck 2008b; Schrader et al. 2011). Thus, since all of the mutant tRNA ${ }^{\mathrm{Ala}} \mathrm{s}$ are able to undergo ribosomal decoding in a manner similar to the wild-type control, it appears that their tertiary structures are not significantly disrupted by any of the structurally conservative mutations. tRNA mutations predicted to disrupt folding often show impaired rates and extents of decoding (Harrington et al. 1993; Pan et al. 2008).

The tRNA ${ }^{\text {Ala }}$ mutations show very different behaviors when decoding the near-cognate ACC and GUC codons in a manner that correlates closely with the tRNA ${ }^{\text {Ala }}$ consensus. All six consensus mutations formed very low levels of dipeptide on both noncognate codons, similar to what is observed for native and wild-type tRNA ${ }^{\text {Ala }}$. Accurate decoding by the consensus mutations is consistent with their presence in the sequences of tRNA ${ }^{\text {Ala }}$ in other bacteria. In striking contrast, 12 of the 16 nonconsensus mutations produced significantly more dipeptide than wild-type tRNA with at least one of the two near-cognate codons. In every case where the amount of dipeptide was great enough to be accurately measured, the observed $k_{\text {pep }}$ was close to $1 \mathrm{sec}^{-1}$, confirming them as misreading mutations. These nonconsensus misreading mutations were distributed throughout the $\mathrm{tRNA}^{\mathrm{Ala}}$ structure, including four of the five base pairs in the anticodon to determine the individual rate constants for these mutations, more thorough kinetic analyses of other tRNA misreading mutations indicate that changes in the rate constants of several steps in the decoding mechanism are altered (Cochella and Green 2005; Ledoux et al. 2009). This enhanced misreading of the U31-A39 mutation presumably accounts for its absence among the sequences of bacterial tRNA ${ }^{\mathrm{Ala}} \mathrm{s}$.

The results of screening all the tRNA ${ }^{\text {Ala }}$ mutations on the cognate and two near-cognate codons are summarized in Figure $2 \mathrm{~B}$ by plotting the fraction of labeled tRNA ${ }_{\mathrm{GCC}}^{\mathrm{Ala}}$ converted to dipeptide at completion. With the cognate GCC codon, native tRNA ${ }^{\mathrm{Ala}}$, the unmodified wild-type tRNA and all 22 mutations produce similar high levels of dipeptide. In addition, they all show rates of dipeptide bond formation in the stem and five of the six tertiary interactions tested. It is noteworthy that, for many of the tRNA ${ }^{\text {Ala }}$ misreading mutations, the amount of dipeptide formed differed significantly between the two near-cognate codons. For example, the G10-C25-A45 tRNA misreads the ACC codon more than the GUC codon, while the U13-A22-A46 tRNA acts oppositely. Finally, there were four nonconsensus mutations (U11-G24, A26-U44, C26-U44, and G30-U40) that showed little product with either near-cognate codon and thus do not appear to be misreading mutations. These mutations may represent exceptions to the otherwise strong correlation between the tRNA ${ }^{\mathrm{Ala}}$ consensus and misreading. Alternatively, a different near-cognate codon may be required to detect misreading with these four tRNA mutations. The observed correlation between the tRNA ${ }^{\text {Ala }}$ consensus and translational accuracy strongly 

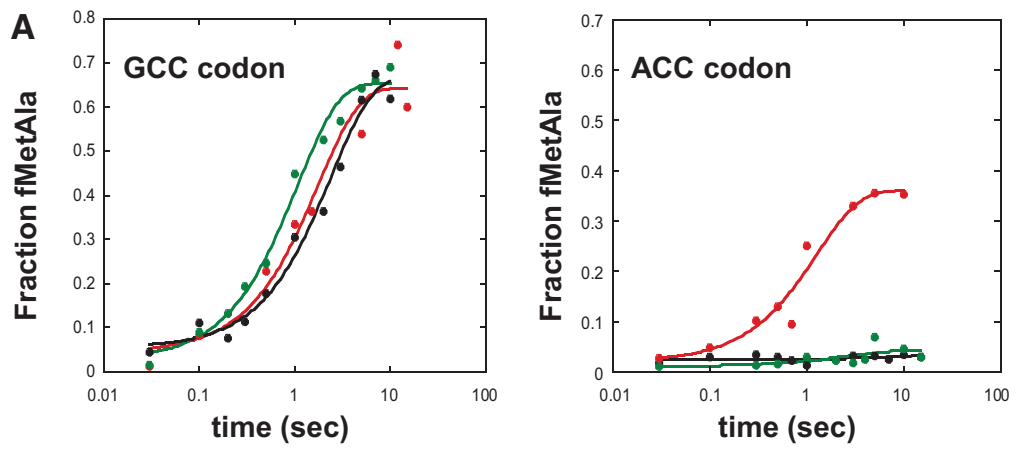

B

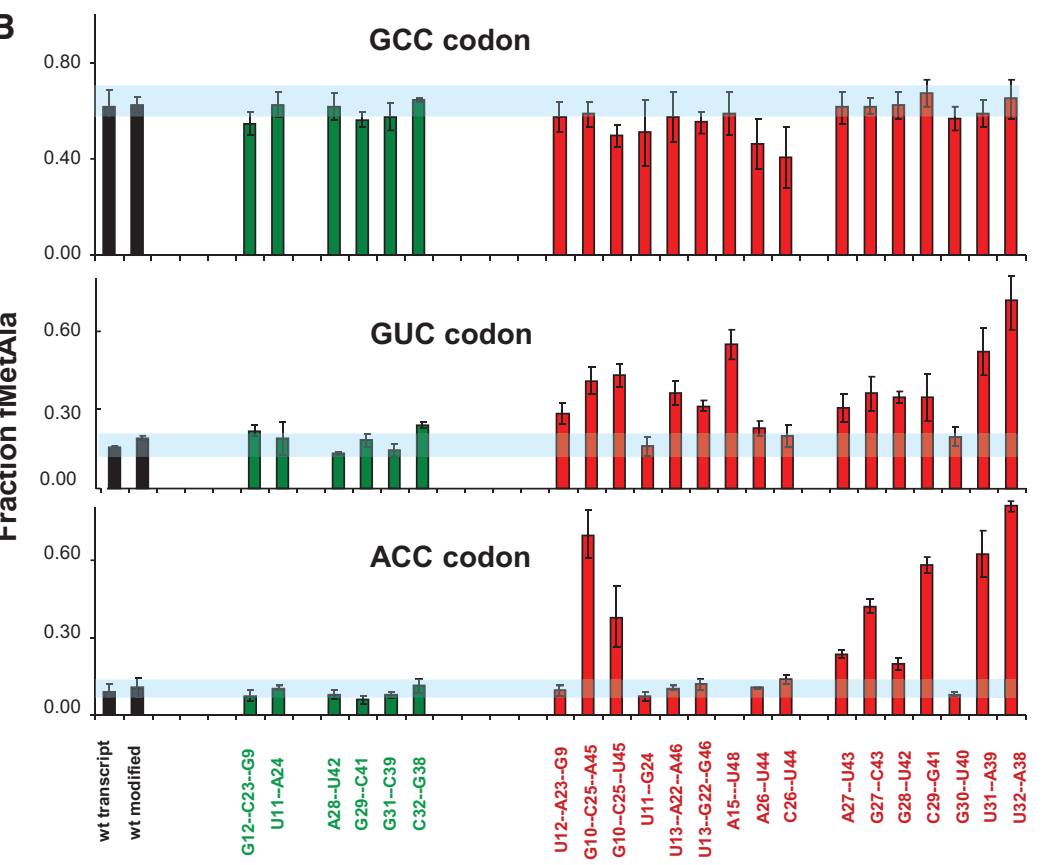

FIGURE 2. Decoding of tRNA ${ }_{\text {GGC }}^{\text {Ala }}$ mutations on cognate and near-cognate codons. $(A)$ Time course of conversion of $\left[3^{\prime}-\mathrm{P}^{32}\right]$ Ala-tRNA ${ }^{\text {Ala }}$ to fMet-Ala-tRNA ${ }^{\text {Ala }}$ for unmodified wild type (black), G31-C39 mutation (green), and U31-A39 mutation (red) using the cognate GCC codon (left) or near-cognate ACC codon (right). (B) Fraction of fMet-Ala-tRNA ${ }^{\mathrm{Ala}}$ formed at completion $(10 \mathrm{sec})$ for native and unmodified tRNA ${ }^{\text {Ala }}$ (black), six consensus mutations (green), and 16 nonconsensus mutations (red) using GCC, GUC, and ACC codons. Horizontal blue bars indicate range of values observed for wild-type tRNA.

suggests that a substantial portion of the bacterial tRNA ${ }^{\mathrm{Ala}}$ sequence has evolved to avoid reading incorrect codons.

How do the structurally conservative nonconsensus tRNA $^{\text {Ala }}$ mutations cause ribosomal misreading? It is likely that different mutations are explained in different ways. Previous experiments have shown that the nonconsensus U32-A38 mutation enhances binding of the ternary complex to near-cognate codons, thereby promoting misreading (Ledoux et al. 2009). A plausible explanation for many of the remaining nonconsensus mutations is based on the observation that the structure of tRNA distorts during decoding (Valle et al. 2002; Frank et al. 2005; Li et al. 2008). Crystal structures of ternary complexes of E. coli RRNA $^{\text {Thr }}$ or tRNA $^{\text {Trp }}$ bound to their cognate codons on Thermus thermo- philus 70 S ribosomes that are blocked just before or after GTP hydrolysis reveal a distorted tRNA conformation in order to accommodate the simultaneous binding of codon with anticodon in the $30 \mathrm{~S}$ subunit and the binding of EF-Tu to its site on the 50S subunit (Schmeing et al. 2009, 2011). In this kinetically trapped decoding intermediate, the anticodon helix is underwound by $14^{\circ}$, and the locations of numerous residues in the tertiary core are altered compared to those expected for the corresponding free-ternary complexes. Many of these residues coincide with the positions where the tRNA ${ }^{\mathrm{Ala}}$ misreading mutations were identified (Fig. 3). Based upon the crystal structures of similar ternary complexes with two different misreading mutations of tRNA ${ }^{\text {Trp }}$, it was proposed that tRNA misreading mutations can access the distorted state more easily, either by selectively stabilizing the structure of the distorted form or destabilizing the structure of the free form (Schmeing et al. 2011). The tRNA sequence changes, therefore, allow the weaker-binding near-cognate codons to have a longer residence time in the bent intermediate state, thereby enhancing their decoding efficiency (Ogle et al. 2002; Yarus et al. 2003; Ogle and Ramakrishnan 2005). Although the precise explanation for how each nonconsensus tRNA $^{\text {Ala }}$ mutation can cause enhanced misreading will require additional kinetic and structural data, they could function in a similar manner as those in $\mathrm{RNA}^{\mathrm{Tr}}$. The details of RNA helix geometry are expected to be affected by the sequence of base pairs, and the flexibility of nucleic acid helices also depends upon sequence (Faustino et al. 2010; Peckham and Olson 2011). Thus, the altered stacking interactions resulting from the base-pair changes in the anticodon helix could alter either the structure or the dynamics of the anticodon helix such that it favors the bent state more easily than the wild-type sequence. A similar explanation could be applied to the core mutations.

The idea that the distortability of a tRNA can explain a substantial portion of the consensus sequence of each individual tRNA has many attractive features. First, since the distortion involves such a large portion of the molecule, it explains why so many nonconsensus tRNA ${ }^{\text {Ala }}$ misreading mutations were identified, including several that do not directly contact the ribosome during decoding. Secondly, the extensive region of bending permits the contribution of many different 

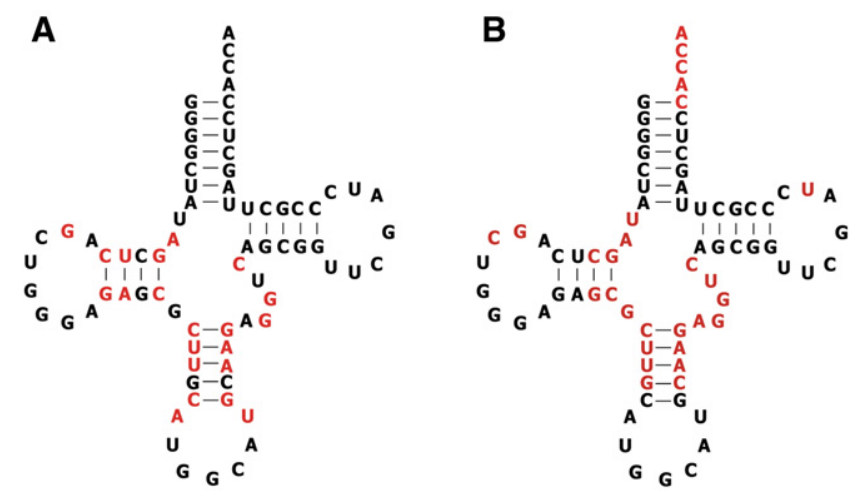

FIGURE 3. (A) Residues in tRNA ${ }_{\text {GGC }}^{\mathrm{Ala}}$ where misreading mutations were found (red). (B) Residues in the tRNA ${ }^{\text {Thr }}$ ternary complex that are distorted upon ribosome binding (Schmeing et al. 2009), mapped onto the sequence of $\mathrm{tRNA}_{\mathrm{GGC}}^{\mathrm{Ala}}$ (red).

combinations of residues to be integrated to achieve the appropriate overall distortability, thereby explaining why the consensus sequences are so redundant in this region of the molecule. While we have not analyzed the effects of making multiple nonconsensus tRNA ${ }^{\mathrm{Ala}}$ mutations on decoding accuracy in much detail, preliminary experiments suggest that the effects of mutations are not additive, indicating that a simple set of sequence rules for misreading may be difficult to deduce. Finally, the bendability concept can also explain the observation that certain base-pair changes in the anticodon helix of tRNA alter its ability to decode its cognate codon (Raftery and Yarus 1987). It seems plausible that the sequence of a tRNA is "tuned" to optimize its bendability for decoding. A tRNA sequence that is too "stiff" will not be able to access the bent state sufficiently easily to decode its cognate codon, while a tRNA sequence that is too flexible will read near-cognate codons too well. The offsetting needs of speed and accuracy is a common theme in the design of the translational machinery (Thompson and Karim 1982; Wohlgemuth et al. 2011; Johansson et al. 2012), so it is not surprising that it is critical in dictating the evolution of tRNA sequences.

If all aa-tRNAs must bend into a similar structure during decoding, why have different tRNA species evolved to have a distinct set of consensus residues in the anticodon helix and core regions? A reasonable possibility is that each consensus evolved in response to the thermodynamic properties of the codon-anticodon interaction. tRNA ${ }^{\mathrm{Ala}}$ and other tRNAs that form stable, GC-rich codon-anticodon complexes will have no difficulty binding ribosomes but have the potential to bind certain near-cognate codons too well. As a result, the consensus sequence of tRNA ${ }^{\text {Ala }}$ and other members of this class have primarily evolved to avoid misreading by possessing sequences that either weaken binding or stiffen the tRNA structure to avoid access to the bent state. This would explain the large number of misreading mutations discovered for tRNA ${ }^{\text {Ala }}$. In contrast, tRNAs with weaker codon-anticodon interactions would be less prone to misreading near- cognate codons, so their consensus sequences evolved to promote binding and enhance bendability. In addition, the tRNAs in this group have all evolved post-transcriptional modifications in the anticodon loop that stabilize the codon-anticodon interaction (Grosjean et al. 2010). Nonconsensus mutations for this second class of tRNAs would be expected to reduce the reading of cognate codons, and relatively few misreading mutations would be found.

The experiments presented here suggest that many of the consensus residues that define the observed sequence diversity of bacterial tRNAs have evolved to maximize accuracy during decoding. However, since the evolution of each tRNA consensus reflects the superposition of the sequence requirements for all the steps in the synthesis, processing, function, and degradation of tRNA, it remains possible that certain consensus residues are also important for some other step in their function. It is interesting that, in the structure of tRNA $^{\text {Phe }}$ bound to E. coli 70 S ribosomes in the hybrid $\mathrm{P} / \mathrm{E}$ site, the anticodon helix is also in a distorted configuration, but the direction and angle of the bend is different than in the decoding complex (Dunkle et al. 2011). Since the entry of tRNAs into the $\mathrm{E}$ site also shows a distinct sequence specificity (Fei et al. 2011), it is possible that some of the tRNA consensus has evolved to optimize this step as well. Since tRNAs bound to near-cognate codons in the P site are also subject to proofreading (Zaher and Green 2009, 2010), it may be that that much of the tRNA consensus has evolved to maintain translational accuracy.

\section{MATERIALS AND METHODS}

Tightly coupled 70S ribosomes from exponential E. coli MRE600 were purified, stored in small aliquots in $50 \mathrm{mM}$ HEPES ( $\mathrm{pH} 7.5$ ), $10 \mathrm{mM} \mathrm{MgCl}_{2}, 70 \mathrm{mM} \mathrm{NH}_{4} \mathrm{Cl}, 1 \mathrm{mM} \mathrm{DTT}$ buffer at $-80^{\circ} \mathrm{C}$, and heat activated before reaction, as previously described (Fahlman et al. 2004). E. coli EF-Tu was purified from a His6-TEV expression clone (Chapman et al. 2012). mRNA fragments (IDT) are derivatives of the T4 gp32 mRNA with the following sequence: $\left(5^{\prime}\right.$ GGCAAGGAGGUAAAAAUGXXXGAACGU-3'), where XXX indicates the codon of interest in the A site. Unmodified E. coli tRNA ${ }_{\text {GGC }}^{\mathrm{Ala}}$ and its mutants were prepared by in vitro transcription by T7 RNA polymerase from templates generated by primer extension of overlapping DNA oligonucleotides (IDT) and purified via $10 \%$ denaturing PAGE. Native tRNA ${ }^{\text {Ala }}$ was isolated from unfractionated E. coli tRNA using an oligonucleotide hybridization protocol (Fahlman et al. 2004). E. coli tRNA ${ }^{\mathrm{fMet}}$ was purchased from SigmaAldrich. tRNAs were $\left[3^{\prime}-{ }^{32} \mathrm{P}\right]$-labeled by tRNA nucleotidyltransferase (Ledoux and Uhlenbeck 2008a) and aminoacylated with purified E. coli AlaRS. Anthraniloyl-tRNA ${ }^{\text {Phe }}$ was prepared from yeast tRNA $^{\text {Phe }}$ as described (Nawrot and Sprinzl 1998).

EF-Tu was converted into its GTP-bound active form by incubating 0.6 $\mu \mathrm{M}$ EF-Tu with $60 \mu \mathrm{M}$ GTP, $3 \mu \mathrm{M}$ phosphoenolpyruvate, 12 units/mL pyruvate kinase in HiFi buffer (50 mM HEPES, pH 7.0, 70 $\mathrm{mM} \mathrm{NH}_{4} \mathrm{Cl}, 30 \mathrm{mM} \mathrm{KCI}, 3.5 \mathrm{mM} \mathrm{MgCl}_{2}, 2 \mathrm{mM}$ DTT, $0.5 \mathrm{mM}$ spermidine, $8 \mathrm{mM}$ putrescine) for $20 \mathrm{~min}$ at $37^{\circ} \mathrm{C}$. Ternary complex was formed by mixing $0.3 \mathrm{mM}$ activated $\mathrm{EF}-\mathrm{Tu}$ with $25 \mathrm{nM}\left[3^{\prime}{ }^{32} \mathrm{P}\right]-\mathrm{la}-$ beled tRNA, incubating at $22^{\circ} \mathrm{C}$ for $10 \mathrm{~min}$ and $0^{\circ}$ for $90 \mathrm{~min}$. The 
rate of peptide bond formation at $22^{\circ} \mathrm{C}$ was performed as described previously (Ledoux and Uhlenbeck 2008a), except that HiFi buffer was used. Equal volumes of $25 \mathrm{nM}$ ternary complex was mixed in a quench-flow device (Kintek) with $0.5 \mu \mathrm{M} 70 \mathrm{~S}$ ribosomes preloaded with $1.0 \mu \mathrm{M}$ fMet-tRNA ${ }^{\mathrm{fMet}}$ and $1.5 \mu \mathrm{M}$ mRNA. As described in Supplemental Figure 1, the $70 \mathrm{~S}$ ribosomes in most reactions also contained $2-8 \mu \mathrm{M}$ of a noncognate aa-tRNA (either Phe-tRNA ${ }^{\text {Phe }}$ or anthraniloyl-tRNA ${ }^{\text {Phe }}$ ) to sequester any free EF-Tu•GTP into ternary complex and thereby prevent multiple turnovers. Each reaction was quenched with $5 \mathrm{mM} \mathrm{NaOAc}, 50 \mathrm{mM}$ EDTA (pH 5.0). Samples were digested by $\mathrm{P} 1$ nuclease, separated and analyzed on PEI cellulose TCL plates in glacial acetic acid/ $1 \mathrm{M} \mathrm{NH}_{4} \mathrm{Cl} / \mathrm{H}_{2} \mathrm{O}$ (5:10:85) buffer. The observed rate of reaction $\left(k_{\text {obs }}\right)$ and extent of dipeptide formation were determined by fitting each curve with a single exponential.

\section{SUPPLEMENTAL MATERIAL}

Supplemental material is available for this article.

\section{ACKNOWLEDGMENTS}

We thank Margaret Saks and Jared Schrader for useful discussions. This work was supported by NIH grant GM037552-25 to O.C.U.

Received August 17, 2012; accepted January 24, 2013.

\section{REFERENCES}

Agris PF. 2008. Bringing order to translation: The contributions of transfer RNA anticodon-domain modifications. EMBO Rep 9: 629-635.

Ardell DH. 2010. Computational analysis of tRNA identity. FEBS Lett 584: 325-333.

Chapman SJ, Schrader JM, Uhlenbeck OC. 2012. Histidine 66 in Escherichia coli elongation factor Tu selectively stabilizes aminoacyl-tRNAs. J Biol Chem 287: 1229-1234.

Cochella L, Green R. 2005. An active role for tRNA in decoding beyond codon:anticodon pairing. Science 308: 1178-1180.

Dunkle JA, Wang L, Feldman MB, Pulk A, Chen VB, Kapral GJ, Noeske J, Richardson JS, Blanchard SC, Cate JH. 2011. Structures of the bacterial ribosome in classical and hybrid states of tRNA binding. Science 332: 981-984.

Fahlman RP, Dale T, Uhlenbeck OC. 2004. Uniform binding of aminoacylated transfer RNAs to the ribosomal A and P sites. Mol Cell 16: 799-805.

Faustino I, Perez A, Orozco M. 2010. Toward a consensus view of duplex RNA flexibility. Biophys $J$ 99: 1876-1885.

Fei JY, Richard AC, Bronson JE, Gonzalez RL. 2011. Transfer RNA-mediated regulation of ribosome dynamics during protein synthesis. Nat Struct Mol Biol 18: 1043-1051.

Frank J, Sengupta J, Gao H, Li W, Valle M, Zavialov A, Ehrenberg M. 2005. The role of tRNA as a molecular spring in decoding, accommodation, and peptidyl transfer. FEBS Lett 579: 959-962.

Giege R, Sissler M, Florentz C. 1998. Universal rules and idiosyncratic features in tRNA identity. Nucleic Acids Res 26: 5017-5035.

Gromadski KB, Rodnina MV. 2004. Kinetic determinants of high-fidelity tRNA discrimination on the ribosome. Mol Cell 13: 191-200.

Gromadski KB, Daviter T, Rodnina MV. 2006. A uniform response to mismatches in codon-anticodon complexes ensures ribosomal fidelity. Mol Cell 21: 369-377.
Grosjean H, de Crecy-Lagard V, Marck C. 2010. Deciphering synonymous codons in the three domains of life: Co-evolution with specific tRNA modification enzymes. FEBS Lett 584: 252-264.

Hagervall TG, Ericson JU, Esberg KB, Li JN, Bjork GR. 1990. Role of tRNA modification in translational fidelity. Biochim Biophys Acta 1050: $263-266$.

Harrington KM, Nazarenko IA, Dix DB, Thompson RC, Uhlenbeck OC. 1993. In vitro analysis of translational rate and accuracy with an unmodified tRNA. Biochemistry 32: 7617-7622.

Johansson M, Zhang JJ, Ehrenberg M. 2012. Genetic code translation displays a linear trade-off between efficiency and accuracy of tRNA selection. Proc Natl Acad Sci 109: 131-136.

Ledoux S, Uhlenbeck OC. 2008a. [ $\left.3^{\prime}-{ }^{32} \mathrm{P}\right]$-labeling tRNA with nucleotidyltransferase for assaying aminoacylation and peptide bond formation. Methods 44: 74-80.

Ledoux S, Uhlenbeck OC. 2008b. Different aa-tRNAs are selected uniformly on the ribosome. Mol Cell 31: 114-123.

Ledoux S, Olejniczak M, Uhlenbeck OC. 2009. A sequence element that tunes Escherichia coli tRNA ${ }_{\text {Gla }}^{\text {GGC }}$ to ensure accurate decoding. Nat Struct Mol Biol 16: 359-364.

Li J, Esberg B, Curran JF, Bjork GR. 1997. Three modified nucleosides present in the anticodon stem and loop influence the in vivo aatRNA selection in a tRNA-dependent manner. J Mol Biol 271: 209-221.

Li W, Agirrezabala X, Lei J, Bouakaz L, Brunelle JL, Ortiz-Meoz RF, Green R, Sanyal S, Ehrenberg M, Frank J. 2008. Recognition of aminoacyl-tRNA: A common molecular mechanism revealed by cryoEM. EMBO J 27: 3322-3331.

Murphy FV IV, Ramakrishnan V, Malkiewicz A, Agris PF. 2004. The role of modifications in codon discrimination by tRNA ${ }_{\text {UuU. }}^{\text {Lys }}$ Nat Struct Mol Biol 11: 1186-1191.

Nawrot B, Sprinzl M. 1998. Aminoacyl-tRNA analogues; synthesis, purification and properties of $3^{\prime}$-anthraniloyl oligoribonucleotides. Nucleosides Nucleotides 17: 815-829.

Ogle JM, Ramakrishnan V. 2005. Structural insights into translational fidelity. Annu Rev Biochem 74: 129-177.

Ogle JM, Murphy FV, Tarry MJ, Ramakrishnan V. 2002. Selection of tRNA by the ribosome requires a transition from an open to a closed form. Cell 111: 721-732.

Pan D, Zhang CM, Kirillov S, Hou YM, Cooperman BS. 2008. Perturbation of the tRNA tertiary core differentially affects specific steps of the elongation cycle. J Biol Chem 283: 18431-18440.

Pape T, Wintermeyer W, Rodnina M. 1999. Induced fit in initial selection and proofreading of aminoacyl-tRNA on the ribosome. EMBOJ 18: $3800-3807$.

Peckham HE, Olson WK. 2011. Nucleic-acid structural deformability deduced from anisotropic displacement parameters. Biopolymers 95: 254-269.

Raftery LA, Yarus M. 1987. Systematic alterations in the anticodon arm make tRNA ${ }^{\mathrm{Glu}_{-}} \mathrm{Su}_{\mathrm{oc}}$ a more efficient suppressor. EMBO J 6: 1499 1506.

Rodnina MV. 2012. Quality control of mRNA decoding on the bacterial ribosome. Adv Protein Chem Struct Biol 86: 95-128.

Saks ME, Conery JS. 2007. Anticodon-dependent conservation of bacterial tRNA gene sequences. RNA 13: 651-660.

Saks ME, Sampson JR, Abelson JN. 1994. The transfer RNA identity problem: A search for rules. Science 263: 191-197.

Schmeing TM, Voorhees RM, Kelley AC, Gao YG, Murphy FV IV, Weir JR, Ramakrishnan V. 2009. The crystal structure of the ribosome bound to EF-Tu and aminoacyl-tRNA. Science 326: 688-694.

Schmeing TM, Voorhees RM, Kelley AC, Ramakrishnan V. 2011. How mutations in tRNA distant from the anticodon affect the fidelity of decoding. Nat Struct Mol Biol 18: 432-436.

Schrader JM, Uhlenbeck OC. 2011. Is the sequence-specific binding of aminoacyl-tRNAs by EF-Tu universal among bacteria? Nucleic Acids Res 39: 9746-9758.

Schrader JM, Chapman SJ, Uhlenbeck OC. 2011. Tuning the affinity of aminoacyl-tRNA to elongation factor Tu for optimal decoding. Proc Natl Acad Sci 108: 5215-5220. 
Targanski I, Cherkasova V. 2008. Analysis of genomic tRNA sets from Bacteria, Archaea, and Eukarya points to anticodon-codon hydrogen bonds as a major determinant of tRNA compositional variations. RNA 14: 1095-1109.

Thompson RC, Karim AM. 1982. The accuracy of protein biosynthesis is limited by its speed: High fidelity selection by ribosomes of aminoacyl-tRNA ternary complexes containing GTP $[\gamma \mathrm{S}]$. Proc Natl Acad Sci 79: 4922-4926.

Urbonavicius J, Qian Q, Durand JM, Hagervall TG, Bjork GR. 2001. Improvement of reading frame maintenance is a common function for several tRNA modifications. EMBO J 20: 4863-4873.

Urbonavicius J, Stahl G, Durand JM, Ben Salem SN, Qian Q, Farabaugh PJ, Bjork GR. 2003. Transfer RNA modifications that alter +1 frameshifting in general fail to affect -1 frameshifting. RNA 9: 760-768.
Valle M, Sengupta J, Swami NK, Grassucci RA, Burkhardt N, Nierhaus KH, Agrawal RK, Frank J. 2002. Cryo-EM reveals an active role for aminoacyl-tRNA in the accommodation process. EMBO J 21: 3557-3567.

Wohlgemuth I, Pohl C, Mittelstaet J, Konevega AL, Rodnina MV. 2011. Evolutionary optimization of speed and accuracy of decoding on the ribosome. Philos Trans R Soc Lond B Biol Sci 366: 2979-2986.

Yarus M, Valle M, Frank J. 2003. A twisted tRNA intermediate sets the threshold for decoding. RNA 9: 384-385.

Zaher HS, Green R. 2009. Quality control by the ribosome following peptide bond formation. Nature 457: 161-166.

Zaher HS, Green R. 2010. Kinetic basis for global loss of fidelity arising from mismatches in the P-site codon: Anticodon helix. RNA 16: 1980-1989. 

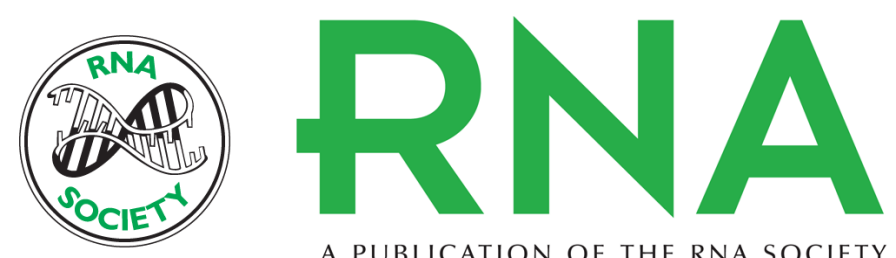

A PUBLICATION OF THE RNA SOCIETY

\section{tRNA residues evolved to promote translational accuracy}

Irina Shepotinovskaya and Olke C. Uhlenbeck

RNA 2013 19: 510-516 originally published online February 25, 2013

Access the most recent version at doi:10.1261/rna.036038.112

Supplemental

Material

References

\section{License}

Email Alerting Service
http://rnajournal.cshlp.org/content/suppl/2013/02/12/rna.036038.112.DC1

This article cites 45 articles, 17 of which can be accessed free at: http://rnajournal.cshlp.org/content/19/4/510.full.html\#ref-list-1 